\title{
Using Four Pelletizing Machines with Flat Die and Different Capacities for Obtaining the Best Pellets from Corn Cobs Waste
}

\author{
Aurel Lunguleasa, ${ }^{\mathrm{a}}$ Cosmin Spirchez, ${ }^{\mathrm{a}, *}$ and Sorin Radulescu ${ }^{\mathrm{b}}$ \\ Making pellets from corn cobs, the goal of this work, was motivated by the \\ abundance of vegetable biomass. Corn is used in both animal and human \\ food. Four pelletizing presses with flat die and different capacities were \\ considered. The influence of the capacity of the pellet mills on the density \\ of the obtained pellets was established by increasing the capacities of the \\ pellet mills to increase the density of the pellets. The waste of crushed \\ corn cobs was used for pelletizing. The energy characteristics of the \\ pellets from corn cobs were determined, with a high calorific value of \\ 20.0MJ. $\mathrm{kg}^{-1}$ and a calorific density of $19.8 \mathrm{MJ} \cdot \mathrm{m}^{-3}$; these values were \\ much higher than the wood species used currently in combustion. The \\ black and calcined ash contents of $24.7 \%$ and $2.3 \%$, respectively, were \\ also obtained. Based on the main properties of experimental pellets, corn \\ cob waste can be regarded as suitable for transformation into pellets with \\ good characteristics. The positive influence of capacity press increase on \\ density of pellets was also highlighted.
}

Keywords: Waste; Corncobs; Pellet; Calorific value; Press capacity; Ash content; Flat die

Contact information: a: Transilvania University of Brasov, Faculty of Wood Engineering, Department of Wood Processing and Design of Wooden Products, 29 Eroilor Blvd, 500036, Brasov, Romania; b: S.C. SARRAS GROUP S.R.L. Brasov, Romania; *Corresponding author: cosmin.spirchez@unitbv.ro

\section{INTRODUCTION}

Vegetable biomass is ubiquitous in agriculture, either in the form of waste from agricultural products used in food, or in the form of waste resulting from animal feeding. The category of vegetable waste biomass with considerable quantities includes vegetable straws (wheat, barley, rye, etc.), hemp and flax waste, sunflower and oil-waste, rice-waste, rapeseed stalks, or other vegetable waste such as lucernes, cane, etc.

The working principle of the pellet mills is the same regardless of whether their die is cylindrical or flat. The small material is forced to penetrate by extrusion into the $6 \mathrm{~mm}$ holes of the die, and thus the pellets are obtained. At the exit from the die the pellets are continuously cut below, obtaining almost equal sizes (some pellets break slightly transversely due to the low resistance in this direction). Above the die, there is a liquefied layer of lignocellulosic material, at a temperature of over $100^{\circ} \mathrm{C}$, which helps compaction. The most important piece in the construction of the pellet mill is the die, which sustains a high force of 20 to 28 tons (Radulescu et al. 2018). This piece is made of steel of the highest quality. It is heat treated for hardening at $1200{ }^{\circ} \mathrm{C}$ and cooled in vacuum to obtain a hardness of 56 to 58 Rockwell units. Because one hole in the matrix produces $0.8 \mathrm{~kg} \cdot \mathrm{h}^{-1}$ pellets, a pellet mill of $200 \mathrm{~kg} \cdot \mathrm{h}^{-1}$ needs about $250 \mathrm{holes}$. It is also recommended that the frequency of passes of a roller on a hole in the matrix is $115 \mathrm{rpm}$; hence, if a $1500 \mathrm{rpm}$ electric motor is chosen, and the gear ratio will be 1:13. The compression ratio is very 
important for the operation of a pellet press. This is the ratio between the thickness of the die and the hole diameter (usually $6 \mathrm{~mm}$ ), which can be 5.3 for straw, 3.2 to 3.5 for fir sawdust, and 3 to 3.3.2 for oak sawdust. Usually this ratio is high for soft species and small for hard species. Therefore, the capacity of a pellet mill is given by the number of holes of the matrix and also by the number of rollers rotating above it.

Corn cobs are cobs without kernels, often used as direct fuel. It has a quasicylindrical shape (slightly taper), with a diameter of about 15 to $35 \mathrm{~mm}$ and a length of 150 to $250 \mathrm{~mm}$ (meaning a volume of 22 to $87 \mathrm{~cm}^{3}$ ). It is made of several distinct areas on the diameter of the cylinder, of which the most important are three: exterior, middle, and inner zones. A white or reddish exterior area is formed from the corn kernels, placed in longitudinal series. This area is rough enough to clean by rubbing different household items, metal burrs, or glass fiber. This part can also be used for polishing varnishes and paints to increase the degree of polish. The middle area of pinkish-white color consists of concentric lignocellulosic rings. It is a very dense area, which makes it suitable to use the whole corn cob at the barbeque. Interior area of white color has a very low density and consists of a single layer (Tang et al. 2013; Yu et al. 2014; Zhang et al. 2015).

Corn cobs have multiple uses. A first characteristic of these is that they retain heat for a long period, as they have a low degree of energy release. In this sense, corn cobs can be used in barbeques due to their high density and higher calorific value. Corn cobs can be used to smoke meat and sausages, thus replacing beech sawdust (Mohlala et al. 2016). When preparing the red-hot coal needed for a barbeque, it is recommended to place pieces of corn cobs under the charcoal so that it will obtain a slight smoke aroma of the roast. Due to the large density of the exterior, these cobs can be transformed by shredding into abrasive particles and are still used for the polishing of fine materials such as fiber glass, and cleaning or removing paint from certain surfaces, such as on boats or cabins. Corn cabs can be used to clean food grills. After it is thoroughly cleaned and washed, a piece of corn cob can be used as a clothes brush. This is facilitated by the alveoli of the existing kernels on the outside of the cob.

Corn (Zea mays) has several types of waste, and corn cob cannot be used directly in animal feed (Takada et al. 2018). It consists of several parts as $21.1 \%$ the outer, $77.5 \%$ the annual rings, and $1.4 \%$ core. The main chemical component is hemicellulose with the main component xylan (arabinose and galactose). Ditzel et al. (2017) investigated the extraction of nano-crystalline cellulose from corn-cobs in comparison to microcrystalline cellulose. After delignification, the amount of nano-crystalline cellulose was $23.5 \%$. These microparticles had great potential for use in polymer composites obtained after extrusion. Mohlala et al. (2016) examined agricultural residues of corn cobs from Africa in order to sustainably cover the growing needs of the population in the energy field. The energy potential of corn cobs in Nigeria and South Africa was estimated. Other benefits of these wastes are also discussed. Da Silva et al. (2015) used corn cobs residues, specifically extracted hemicelluloses, in the production of kraft eucalyptus pulp. Two hemicellulose fractions were used, one obtained after neutralization and precipitation of the alkaline solution, and the second after the addition of ethanol in the same solution. An increase in mechanical properties was observed with the increase in hemicellulose content obtained from corn cobs. Miranda et al. (2018) state that pellets are bio-fuels with high energy potential because domestic stoves and boilers need high quality fuels. For experiments a semi-industrial pelletizing machine was used, and the pellets obtained from corn cobs were analyzed in terms of bulk density and durability. The obtained results corresponded to the standards. Kaliyan and Morey (2010) used a briquetting unit with a uni-axial piston with a 
maximum pressure of $150 \mathrm{MPa}$. The particle sizes of corn cobs were $0.85 \mathrm{~mm}$ and 2.81 $\mathrm{mm}$, these being heat treated at temperatures of 25 to $85{ }^{\circ} \mathrm{C}$, obtaining briquettes with a diameter of $19 \mathrm{~mm}$. Regardless of the particle size and heat treatment temperatures, a density of briquettes over $1100 \mathrm{~kg} \cdot \mathrm{m}^{-3}$ and a mechanical durability over $90 \%$ were obtained. Similar results were obtained by El-Sayed and Khairy (2017), Paiva et al. (2012), and Kundu et al. (2018).

Pinto et al. (2012) studied the microstructure and macrostructure of corn material, the elemental chemical composition, density, water absorption, fire resistance and thermal insulation capacity, as compared to expanded polystyrene and extruded polystyrene, as classic insulation material in the construction industry. There are similarities between these construction materials, but the new materials contribute to a more environmentally friendly construction industry. Zang et al. (2019) prepared a new composite, consisting of the incorporation of stearic acid into a die of carbonized corn cobs. This new composite has a highly porous structure, a latent heat of $144.2 \mathrm{~J} \cdot \mathrm{g}^{-1}$, excellent thermal stability and high performance of the composite stability in constructions.

Wang et al. (2018) impregnated corn cobs with pickle liquor (obtained from surface treatment of iron and steel) to obtain magnetically activated carbon. After impregnation, the corn cob material was dried at $120^{\circ} \mathrm{C}$ for $24 \mathrm{~h}$, and carbonized at 300,500 , and $700^{\circ} \mathrm{C}$. The composite contains hematite $\left(\mathrm{Fe}_{2} \mathrm{O}_{3}\right)$ and magnetite $\left(\mathrm{Fe}_{3} \mathrm{O}_{4}\right)$, which have higher magnetization capacity with higher carbonization temperatures. Njeumen-Nkayem et al. (2016) studied the introduction of different percentages $(2,5,10$, and $15 \%$ ) of corn cobs in the production of high porosity ceramic bricks. Different temperatures of burning of the bricks of 900,1000 , and $1100{ }^{\circ} \mathrm{C}$ were used. The physical-mechanical properties increased with increasing temperature and decreased with increasing percentage of corn cobs. Laohalidanond et al. (2017) and Biagini et al. (2014) stated that the properties of corn cobs can be improved by torrefaction. The study was focused on the gasification process of raw cobs and torrefied cobs as solid fuel. The gas obtained by this process was determined by its composition and calorific value, and finally the gasification efficiency for raw cobs and torrefied raw cobs were obtained. Better gasification was obtained for the torrefied material. The gas obtained from raw cob gasification contained more CO (18 to 27\% by volume), $\mathrm{H}_{2}$ ( 3 to $9 \%$ by volume), and $\mathrm{CH}_{4}$ ( 0.1 to $0.3 \%$ by volume), compared with values of $5.5 \% \mathrm{CO}, 0.9 \% \mathrm{H}_{2}$, and $0.03 \% \mathrm{CH}_{4}$. A high value of $\mathrm{CO}, \mathrm{H}_{2}$, and $\mathrm{CH}_{4}$ led to a higher calorific value of the cobs, increasing from $0.835 \mathrm{MJ} \cdot\left(\mathrm{Nm}^{3}\right)^{-1}$ for raw cobs to 2.8 to 4.2 $\mathrm{MJ} \cdot\left(\mathrm{Nm}^{3}\right)^{-1}$ for torrefied cobs.

Lao and Giusti (2018) analyzed the use of raw cobs in the food industry for the extraction of food pigments. The paper used aqueous ethanol, a consumer-friendly product. This pigment obtained from raw cobs has a good potential for use in the food field as red pigment. Du et al. (2015) studied the obtaining of raw corn cobs of high-quality syngas, consisting exclusively of $\mathrm{H}_{2}$ and $\mathrm{CO}$, and as remaining high-quality solid carbon. An $82 \%$ carbon conversion rate, $39 \% \mathrm{CO}$ selectivity and an $\mathrm{H}_{2} / \mathrm{CO}$ ratio greater than 1.5 were obtained. Biswas et al. (2017) studied pyrolysis of various wastes, including corn cobs at temperatures of 450 and $400{ }^{\circ} \mathrm{C}$. The maximum amount of bio-oil was from corn cobs of $47 \mathrm{wt} \%$.

Pinto et al. (2011) analyzed the use of corn cobs as a building material for exterior walls in Portugal. The experiments showed the potential of using these agricultural wastes as insulation material, similar to extruded polystyrene, as microstructure. Faustino et al. (2012) studied the use of corn cobs as particleboard in the construction of houses, as thermal insulation products, ceiling and wall coverings, and interior doors. The acoustic 
insulation properties of the low weight pallet were obtained. A $3 \mathrm{~mm}$ layer was placed on the floors and compared with classic materials such as glass wall and expanded polystyrene, or with other natural insulation materials such as kenaf, coco fiber, sheep wool, cork, and cellulose. Wongsiriamnuay and Tippayawong (2015) found that a torrefaction temperature of 60 to $80^{\circ} \mathrm{C}$ is suitable for obtaining stable pellets with a density up to $1000 \mathrm{~kg} / \mathrm{m}^{3}$. The results obtained by Zang et al. (2018) highlighted the fact that the highest value of calorific value was obtained when corn cobs are thermally treated in a humid environment for up to half an hour. Djatkov et al. (2018) demonstrated that denser pellets are obtained by increasing the compression ratio to 4 or reducing the particle size. Onsree et al. (2019) made a comparison between native pellets and those treated in a humid environment from corn cobs, observing a better grindability, a higher porosity, and a high decomposition of hemicelluloses in steam-treated pellets. Zhang et al. (2019) used the corn cobs obtained from the anaerobic digestive process, processed by wet and dry torrefaction, to obtain pellets that will be used in combustion. The conclusion of the study shows that the torrefied pellets in wet environment will burn faster while the burning of torrefied pellets by the dry process will be much more stable.

In sum, there are many applications of corn cobs that include direct use as fuels. The use of corn cobs for making pellets has been only mentioned, but no consistent studies have been performed in this field. The objective of this paper is to make high quality pellets using corn cob waste on four pellet installations with different capacities. To find the optimal solutions of the properties of particles and pellets, the experiments were intended to determine the physical properties such as dimensions and density, then the calorific properties such as the high, low, calorific value and the calorific density, and finally some chemical properties such as the content of black and calcined ash. Finally, the influence of the capacity of the pellet pressing installations on the pellet density was determined.

\section{EXPERIMENTAL}

\section{Raw Material}

The waste of cobs taken from Brasov region of Romania (production of 2019) was crushed in a small lab hammer mill (Fig. 1).

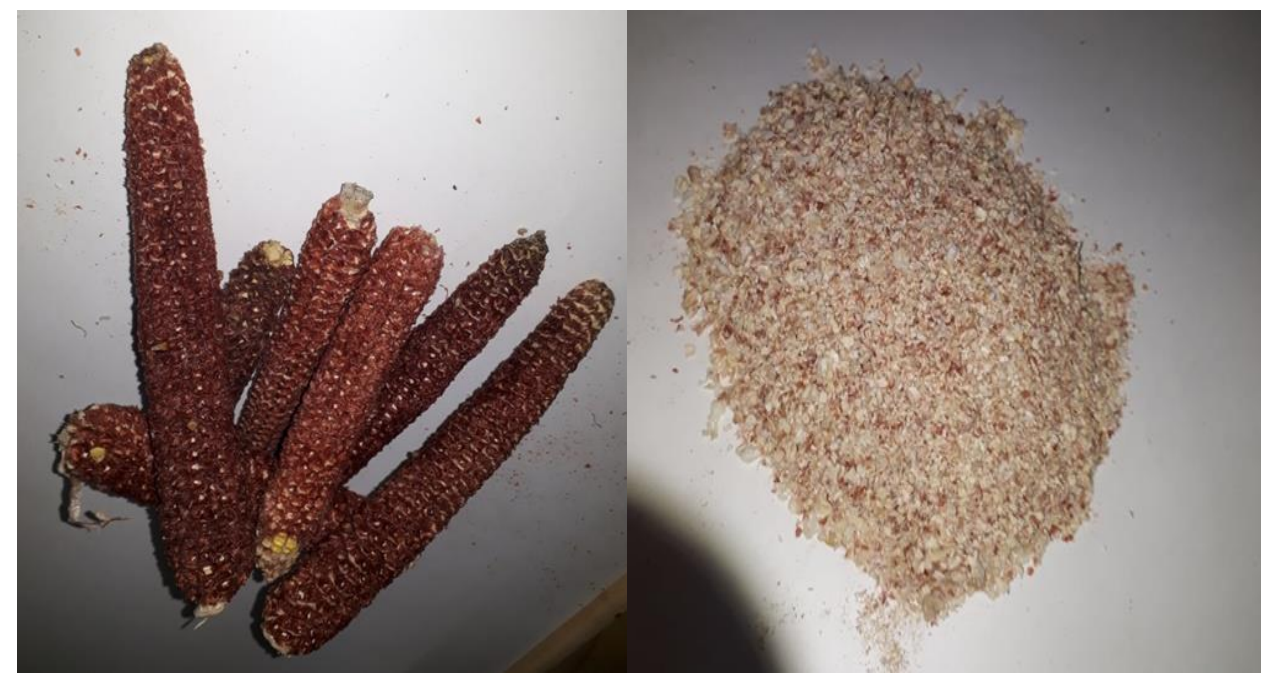

Fig. 1. Corn cobs as raw material (left) and ground (right) 
Prior to processing, the crushed material was conditioned by keeping it in a controlled environment with a constant temperature of $20{ }^{\circ} \mathrm{C}$ and a relative humidity of $65 \%$. The particle size of this material was determined using an electric vibration device and the sieves (EN 15149-1 2010) with sizes of 3.15, 2, 1.25, 0.8, and $0.4 \mathrm{~mm}$. The material collected under the $0.4 \mathrm{~mm}$ sieve was called "Rest". Because the size of these sieves did not have a constant decreasing step, there were made a modeling of the sieve values with a constant step.

\section{Determination of the Density of the Pellets}

This shredded material (Ragland et al. 1991) was introduced in the pellet press, eliminating the first 50 to 80 pieces that had defects of compaction, because the optimum pelletizing temperature of over 90 to $100{ }^{\circ} \mathrm{C}$ is obtained after some passage of time and not at the beginning of the pelletizing. Main components of a pelletize press are die and rollers (Fig. 2). If the pelletizing machine is new, an operational test is performed using pure cellulose or the waste of finely chopped newspapers. At the end of the pelletizing operation, flax oil is placed on the die of the machine so as not to block the pellets remaining in the die at the next operation of pelletizing.

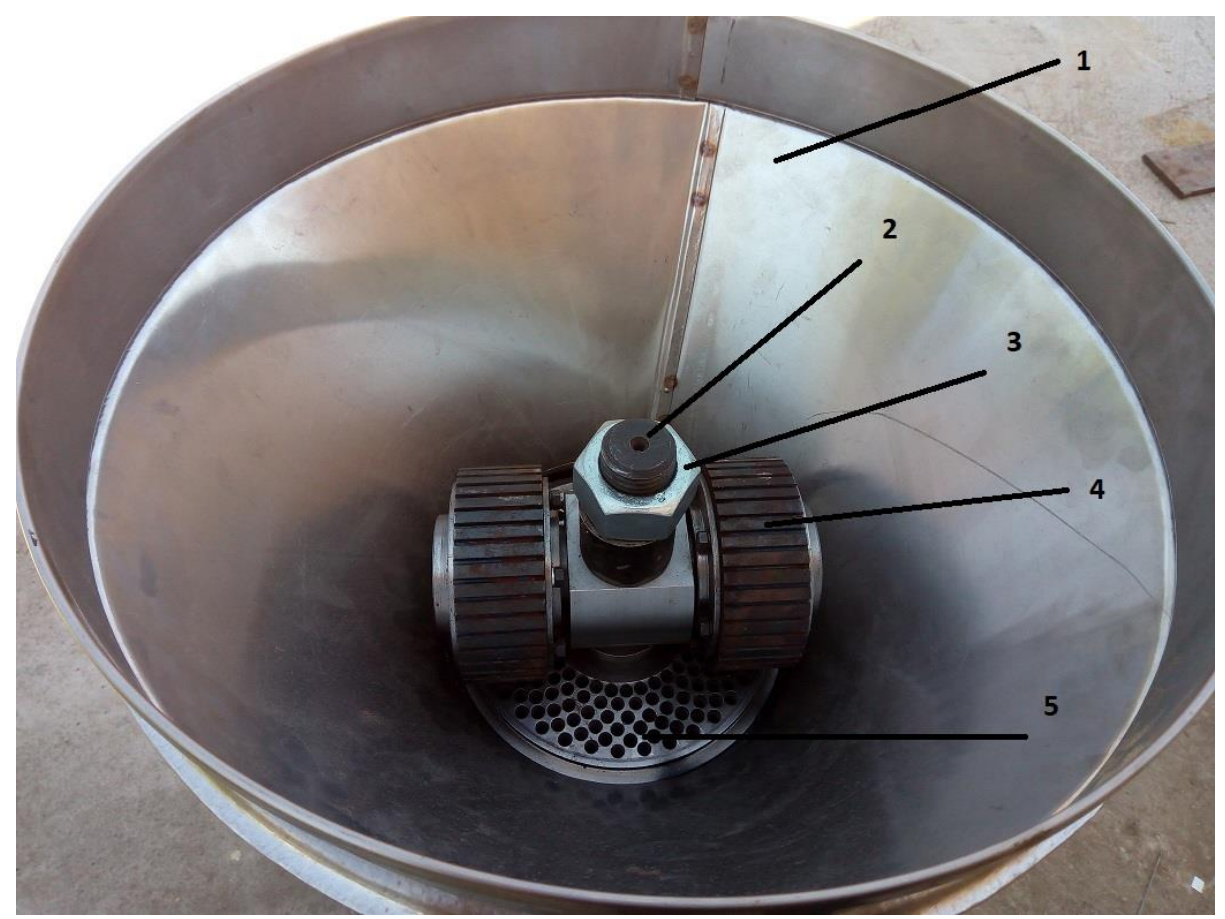

Fig. 2. Pelletizing press D50 (top view): 1-cone, 2-threaded screw, 3-nut, 4-pressing roll, and 5-die

To determine the moisture of the pellets, the standard EN 14774-3 (2009) was used, namely the weighing-drying-weighing method, using a scale and a laboratory oven.

For the determination of the pellet density, the standards EN ISO / IEC 323 (2005) and EN 15103(2000) were used. To determine the effective density of the pellets, 20 pieces of pellets made from corn cobs were obtained from each type of pellet, i.e., those obtained from the pellet mills of $20 \mathrm{~kg} / \mathrm{h}$ (noted D20), $200 \mathrm{~kg} / \mathrm{h}$ (D200), $400 \mathrm{~kg} / \mathrm{h}$ (D400) and 500 $\mathrm{kg} / \mathrm{h}$ (D500). The pellet ends were straightened by grinding on the abrasive disc so that the surface was smooth to determine the exact length. Equation 1was used to determine the effective density (determined by the cylindrical shape of the pellet), 


$$
\rho=\frac{4 m}{\pi \cdot d^{2} \cdot l} \cdot 10^{6}\left[\mathrm{~kg} \cdot \mathrm{m}^{-3}\right]
$$

where $\rho$ is the effective density of the pellets $\left(\mathrm{kg} \cdot \mathrm{m}^{-3}\right), m$ is mass of the pellets $(\mathrm{g}), d$ is diameter of the pellets $(\mathrm{mm})$, and $l$ is length of the pellets $(\mathrm{mm})$.

The bulk density of the pellets was determined using a conical vessel of $45.31 \times 23.43$ $\times 99.01 \mathrm{~mm}$ and Eq. 2 (EN 15103 2009; EN 15150 2012),

$$
\rho_{b}=\frac{3 \cdot\left(m_{s w}-m_{e w}\right)}{\pi \cdot h \cdot\left(R^{2}+r^{2}+R r\right)} \cdot 10^{6}\left[\mathrm{~kg} \cdot \mathrm{m}^{-3}\right]
$$

where $\rho$ b is bulk density $\left(\mathrm{kg} \cdot \mathrm{m}^{-3}\right), m_{\mathrm{sw}}$ is the mass of pellets, including the empty vessel $(\mathrm{g})$, $m_{\text {ew }}$ is mass of empty vessel $(\mathrm{g}), R$ is large radius of cone trunk, equal to $45.31 \mathrm{~mm}, r$ is the small radius of the cone trunk, equal to $23.43 \mathrm{~mm}$, and $h$ is the height to which the level of the pellets in the recipient reaches. Usually the maximum level of $99.01 \mathrm{~mm}$ was used. The final result was the arithmetic mean of 10 values performed on the pellets batch. The bulk density of corn cobs particles, also given by the loosening coefficient of lignocellulosic material, was determined in a vessel with a volume of $822.1 \mathrm{~cm}^{3}$.

\section{Determination of the Caloric Value of the Pellets}

The determination of the calorific value for the pellets in corn cobs is almost similar to that of coal (as solid fuel) and with few differences with respect to liquid fuels (gasoline, diesel, etc.) or gases (methane gas, LPG, biogas, etc.). Generally, the method for determining the calorific value is done separately for solid fuels (ASTM D3865-122000) or liquids and gasses. For comparing the calorific value, the limitative values provided by standard ÖNORM M7135 (2000) were used.

A total of at least 5 or 8 validly tested experimental samples were used (DIN 519001 2000; EN 14918 2010; Tumuluru et al. 2011). The experiments were performed on 10 samples. An XRY-1C explosive combustion calorimeter (Shanghai Changji Geological Instrument Co., Shanghai, China) was used to determine the calorific value of corn cob pellets. Before performing the test, the calorimeter bomb was calibrated with benzoic acid, which has a known calorific value (usually $26,463 \mathrm{~kJ} \cdot \mathrm{kg}^{-1}$, or with small differences of maximum $\pm 1 \%$ ). The calorimetric coefficient $(k)$ of the calorimetric installation was calculated using Eq. 3,

$$
P C S_{s}=k \cdot\left(\frac{\left(t_{f}-t_{i}\right)}{m_{l}}\right)-q_{s}-q_{b}\left[\mathrm{~kJ} \cdot \mathrm{kg}^{-1}\right]
$$

where $k$ is the calorimetric coefficient, which is determined by calibration with benzoic $\operatorname{acid}\left(\mathrm{kJ} \cdot{ }^{\circ} \mathrm{C}^{-1}\right), t_{\mathrm{f}}$ is the final temperature $\left({ }^{\circ} \mathrm{C}\right), t_{\mathrm{i}}$ is the initial temperature $\left({ }^{\circ} \mathrm{C}\right), m_{1}$ is the mass of corn cob pellets $(\mathrm{kg}), q_{\mathrm{s}}$ is the heat obtained by burning the nickel wire $\left(\mathrm{kJ}^{\mathrm{kg}} \mathrm{kg}^{-1}\right)$, and $q_{\mathrm{b}}$ is the heat obtained by burning cotton yarn $\left(\mathrm{kJ} \cdot \mathrm{kg}^{-1}\right)$.

The calorific value of the pellets from corn cobs refers first to the preparation of the pellets and the installation, then to the actual test, and finally to the final result (of the high and low calorific value, and the burning time). The material for testing was $0.8 \mathrm{~g}$ of pellet, weighed to an accuracy of 4 decimals. This sample was placed in a non-melting metal crucible and inserted into the bomb for testing. Approximately 30 bars of oxygen were introduced into the bomb. The bomb was placed in a calorimeter such that the water was exactly at the upper level of the bomb. The two direct wires were connected to the bomb and the cover was closed. Next, it was necessary to introduce in the computer software the exact mass (with an accuracy of 4 decimals), the name of the sample, and the calorimetric coefficient. Finally, the actual test was initiated with the pressing of a button. 
The test has three distinct periods, called "fore", "main", and "after". After stabilizing the temperature in the first stage, so there was no difference between two consecutive values of the temperature. Electrical current was introduced to ignite the cotton thread and the pellet. By burning the pellet, a certain amount of heat is released, highlighted by the increase in temperature during the main period. At the end of the main period (when the temperature does not increase anymore), the calculation temperature $t_{\mathrm{f}}$ was obtained, based on which the low and high calorific value. During the after period, the temperature value was validated or corrected by computer software. The final result given by the installation software was in the form of a table with the sample and test data, with all the values of the temperature for the three periods, as well as the values of the high and low caloric power and the duration of the test.

\section{Determination of the Pellet Calorific Density}

The calorific value per unit of volume was calculated as follows,

$$
C D=C V \cdot \rho_{p} \cdot 10^{-6}\left[\mathrm{MJ} \cdot \mathrm{m}^{-3}\right]
$$

where $C V$ is the calorific value of pellets from corn cob waste $\left(\mathrm{kJ} \cdot \mathrm{kg}^{-1}\right)$, and $\rho_{\mathrm{p}}$ is the effective pellet density $\left(\mathrm{kg} \cdot \mathrm{m}^{-3}\right)$. This parameter is a convenient value for wood fuels and typical for pellets. The calorific value $\mathrm{CV}$ of the pellets is a constant value of the used species, different from the high HCV and low LCV, being independent of the moisture content, because it is calculated for a moisture content of $0 \%$ with the following equation,

$$
C V=\frac{L C V_{M c}}{100(100-M c)}-\frac{2.44 \cdot M c}{100-M c}\left[\mathrm{KJ} \cdot \mathrm{kg}^{-1}\right]
$$

where $L C V_{\mathrm{Mc}}$ is low calorific value at a certain moisture content $\left(\mathrm{kJ} \cdot \mathrm{kg}^{-1}\right), M_{\mathrm{c}}$ is moisture content $(\%)$.

Another method of finding the calorific value $\mathrm{CV}$ is to plot the linear regression equations through repeated experiments of the pellets with different moisture content, such as for $M_{\mathrm{cw}}=10$ and $30 \%$ and obtaining intersecting points of the HCV curves and LCV on Oy axis.

\section{Determination of Black and Calcined Ash Content}

ASTM D-1102 (1984), EN 14775 (2010), and ISO18122 (2015) were used to determine the ash content. An analytical scale with the measuring range between $0.001 \mathrm{~g}$ and $100 \mathrm{~g}$ was used. The mass of the empty crucible and the mass of the crucible with the sample to be analyzed were determined. First, the crushed material is burned under a flame of gas to protect the calcination furnace against soaking the walls with soot. In this way the percentage content of black ash is obtained. The weighed sample will be inserted into the calcination furnace, being heated to $750 \pm 10{ }^{\circ} \mathrm{C}$. After reaching the mentioned temperature, the samples are placed in the calcination furnace for $60 \mathrm{~min}$, after which they will be removed and left to cool in desiccators for $5 \mathrm{~min}$. After reaching the ambient temperature, the crucibles with calcined material will be weighed, determining the mass of the crucible with residue after calcination. The ash content of the sample is calculated as a ratio between the mass of the residue obtained after calcination and the initial mass of the analyzed sample, as follows,

$$
A_{c}=\frac{m_{a+c}-m_{c}}{m_{s+c}-m_{c}} \cdot 100[\%]
$$

where $m_{\mathrm{c}}$ is mass of empty crucible $(\mathrm{g}), m_{\mathrm{a}+\mathrm{c}}$ is mass of crucible with calcined ash $(\mathrm{g})$, and 
$m_{\mathrm{s}+\mathrm{c}}$ is mass of crucible with dry crushed sample $(\mathrm{g})$.

\section{Statistical Analysis}

The evaluation of physical and mechanical properties of pellet was statistically analyzed using Minitab 18 software. The comparative analysis was applied based on probability plot with a confidence interval (CI) corresponding to $95 \%$ confidence, and interval plots in order to highlight the differences between the different pellet types.

\section{RESULTS AND DISCUSSION}

\section{The Raw Material}

The average particle size of the crushed material was $1.7 \mathrm{~mm}$, similar to previous reports (Ragland et al. 1991; Kaliyan and Morey 2010). The results obtained by using the effective sieves (Fig. 3) was modeled by a polynomial equation of $2^{\text {nd }}$ degree with the coefficients $(-3.787 ; 25.71 ;-15.89)$, in order to have a constant step from 0.5 to $0.5 \mathrm{~mm}$, also obtaining a polynomial equation of $2^{\text {nd }}$ degree, but with different coefficients $(-7.968$; $28.01 ;-1.601)$ as can be observed in Fig. 3b. The modeling consisted of taking each range, dividing it into value units, and adding to the initial value a value corresponding to the analyzed range. The difference between the coefficients of the polynomial equation showed that the modeling was appropriate. By zeroing the derivative of the first order of the newly obtained polynomial equation, the peak and the middle of the polynomial curve $(1.7 \mathrm{~mm})$ with a good precision of $\mathrm{R}^{2}=0.69$ were obtained. Within the initial polynomial equation, the peak was different.

The average value of the four values from Fig. 4 was $681.9 \mathrm{~kg} \cdot \mathrm{m}^{-3}$.

\section{The Density of the Pellets}

The moisture content of the pellets used in the experiments was approximately $8.0 \%$, which is within the limits of ÖNORM M7135 (2000), with values below 12\%. The bulk density of the pellets determines the volume of bagging of the pellets, and it differs depending on the capacity of the pellet press, having an increasing evolution with increasing the installation capacity. This bulk density depends mainly on the mass of the pellets, but also on the sizes (length) of the pellets (Miranda et al. 2018). Due to the increase in density regard on capacity press, it can be concluded that the volumetric mass of the pellets has an overwhelming influence on it and less their length (because the pellets can be easily sheared in length during the manufacturing period). That is why the weight of the briquettes remains the only factor that increases the bulk density. The average value of the four values from Fig. 4 was $681.9 \mathrm{~kg} \cdot \mathrm{m}^{-3}$. 
a.

b.
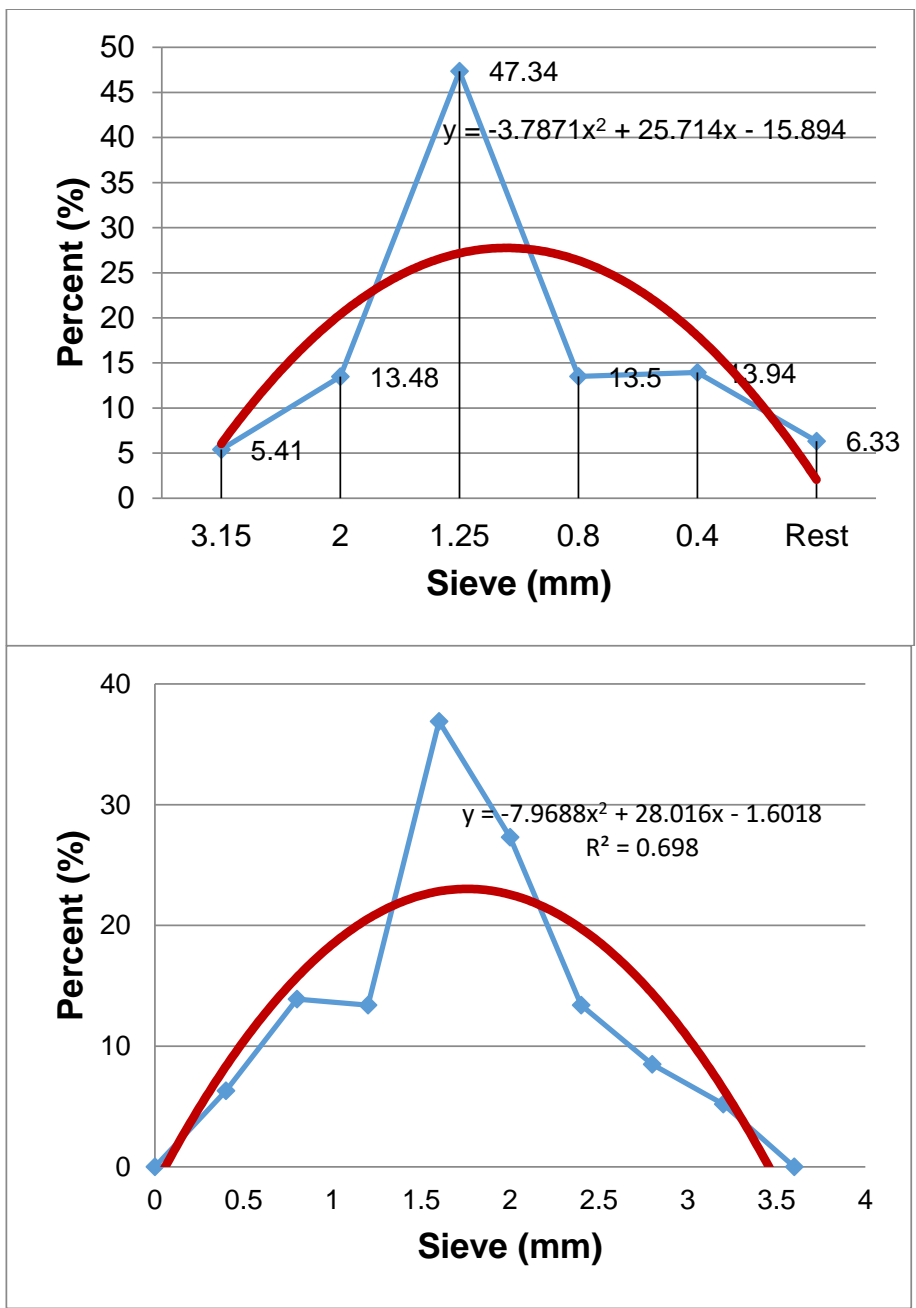

Fig. 3. Granulometry of corn cobs particles: (a) experimental and (b) modeling values

\section{The Density of the Pellets}

The moisture content of the pellets used in the experiments was approximately8.0\%, which is within the limits of ÖNORM M7135 (2000), with values below $12 \%$. The bulk density of the pellets determines the volume of bagging of the pellets, and it differs depending on the capacity of the pellet press, having an increasing evolution with increasing the installation capacity. This bulk density depends mainly on the mass of the pellets, but also on the sizes (length) of the pellets (Miranda et al. 2018). Due to the increase in density in regards on capacity press, it can be concluded that the volumetric mass of the pellets has an overwhelming influence on it. The pellets can be easily sheared in length during the manufacturing period. That is why the weight of the briquettes remains the only factor that increases the bulk density. 


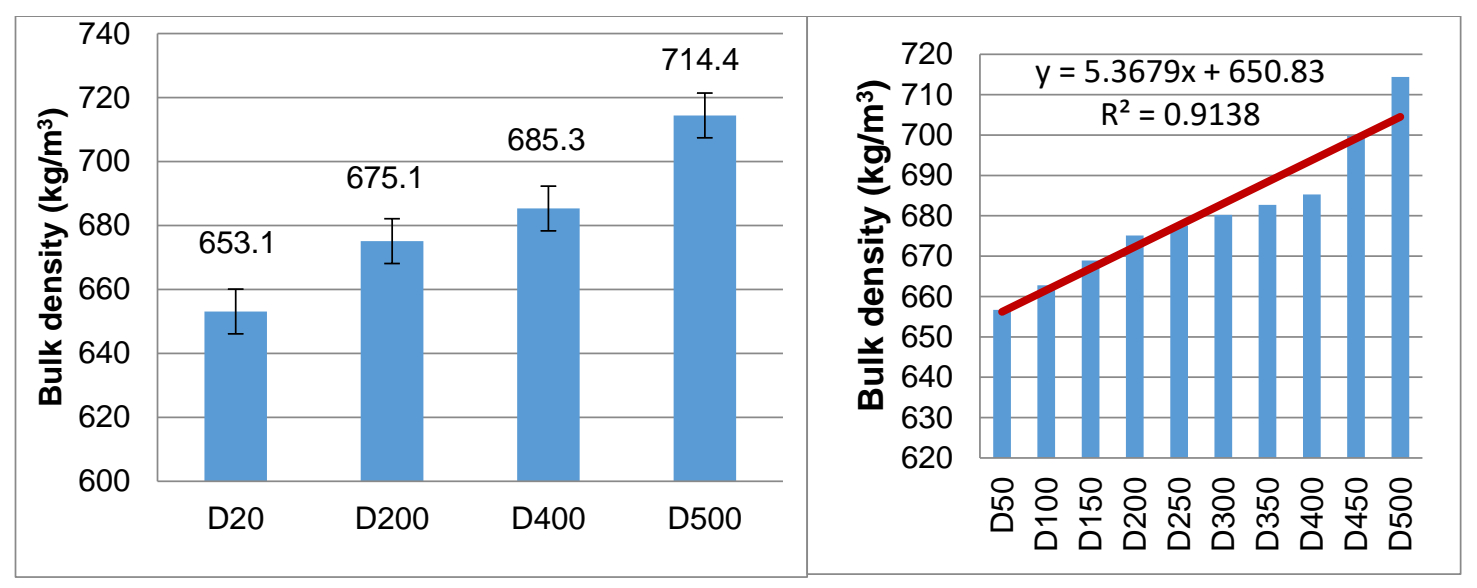

a.

b.

Fig. 4. Bulk density of pellets: (a) experimental and (b) modeling values

The capacity of pellet installations did not have a constant growth index, which is why the bulk density was modeled, for hypothetical cases of presses with equidistant capacities (Fig. 3b). The coefficient of variation $\mathrm{R}^{2}$ with a value of 0.913 shows that the regression equation was well chosen.

The effective density of the pellets of the 4 types ranged within the limits of 1160 to $1260 \mathrm{~kg} \cdot \mathrm{m}^{-3}$ and was on average $1215 \mathrm{~kg} \cdot \mathrm{m}^{-3}$ (Fig. 5). The reference value of the Austrian standard ÖNORM M7135 (2000) is over $1100 \mathrm{~kg} \cdot \mathrm{m}^{-3}$. All pellets from the experiments fell within this norm and were greater than the values found by Kaliyan and Morey (2010). As a general rule, with the increase of the capacity of the pelletizing press, the density of the pellets increased, but in small limits of maximum $92.25 \mathrm{~kg} / \mathrm{m}^{3}$ from D50 to D500. The explanation is given by the increasing thickness of the die depending on the capacity of the presses, in order to compensate the tensions that press on them. The thicker the die, the longer the extrusion channel, the higher the extrusion pressure and the higher the density of the obtained pellets.

In Fig. 5, the percentage probability plot was observed as two examples for the pellets obtained on the laboratory pellet instalation $(20 \mathrm{~kg} / \mathrm{h})$ and the industrial one $(500$ $\mathrm{kg} / \mathrm{h}$ ). In this figure the limits of the 20 values variation, the standard deviation, and other statistical parameters are observed. As in the bulk density analysis, due to the different capacity of the pellet mills, it was necessary to model the densities obtained on the existing pelletizing presses (Fig. 6a), finding capacity values (Fig. 6b) for hypothetical press with indexed capacities of $50 \mathrm{~kg} / \mathrm{h}$ step. 


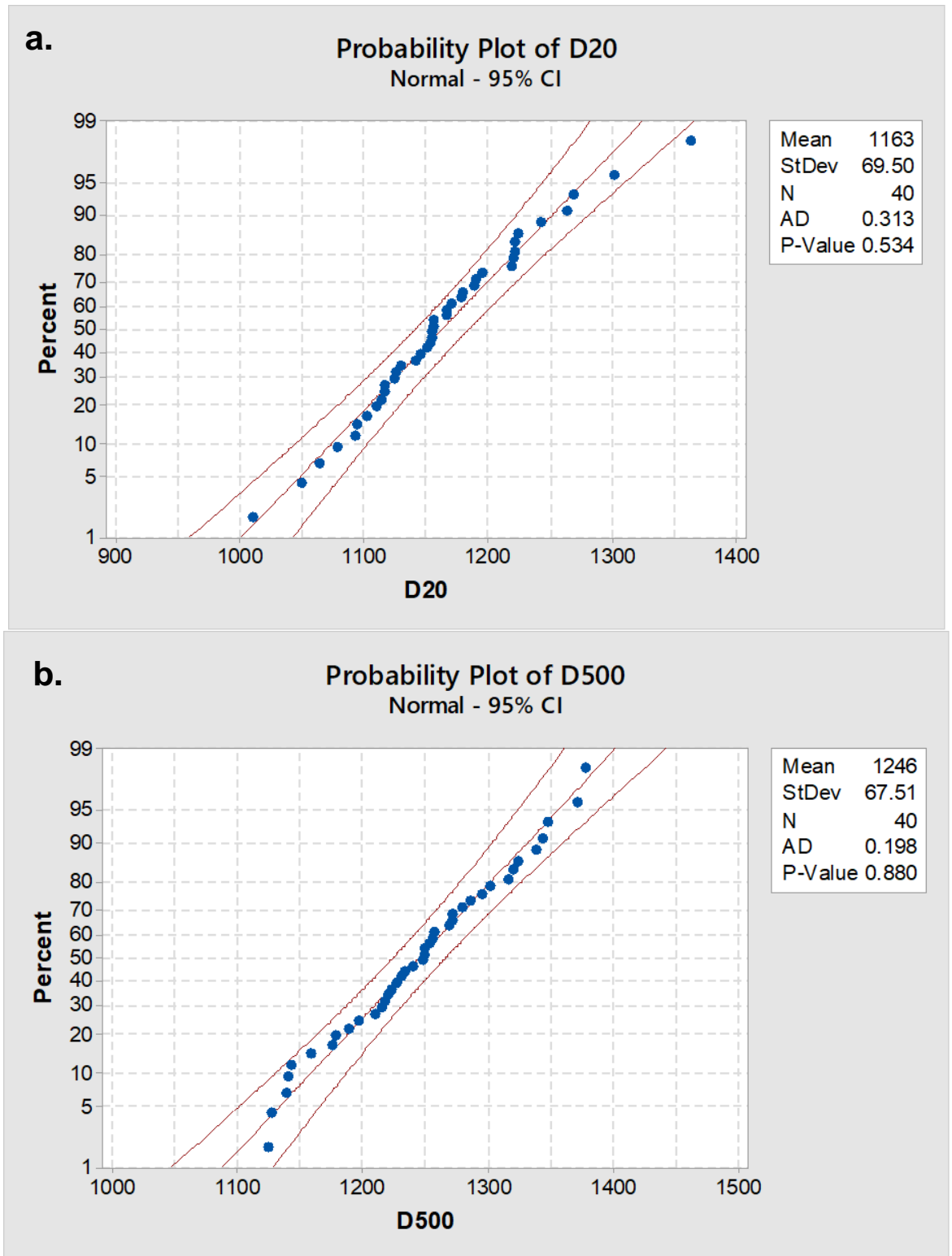

Fig. 5. Percentage probability plot of density for D20 (a) and D500 (b) installations

The obtained regression curve (with a very good coefficient of determination $\mathrm{R}^{2}=$ 0.99, Fig. 6b) identifies density of the pellets for other press capacities that are not found on the initial curve. Each point 1, 2,3, .., 10 represents a capacity increase step of $50 \mathrm{~kg} \cdot \mathrm{h}^{-}$ ${ }^{1}$ corresponding to a density increment of $10.32 \mathrm{~kg} \cdot \mathrm{m}^{-3}$. With direct referencing to this algorithm, two examples are presented below:

- for D550, meaning for the point $x=11$ the result is:

$$
y=10.32 \times 11+1157=1270.5 \mathrm{~kg} \cdot \mathrm{m}^{-3} ;
$$

- for D420, meaning at $x=8+i$, an increment $i$ is added to the value of D400:

$$
y=10.32 \times 8+1157+(1255.3-1245.6): 10 \times 2=1245.6+1.94=1247.5 \mathrm{~kg} \cdot \mathrm{m}^{-3} \text {. }
$$

This modeling determines the density of the pellets obtained with a certain installation. In addition, the graph from Fig. $5 \mathrm{~b}$ provides a direct way of finding density by 
raising a vertical to cut the linear equation and then the horizontal line intersection to the vertical axis.
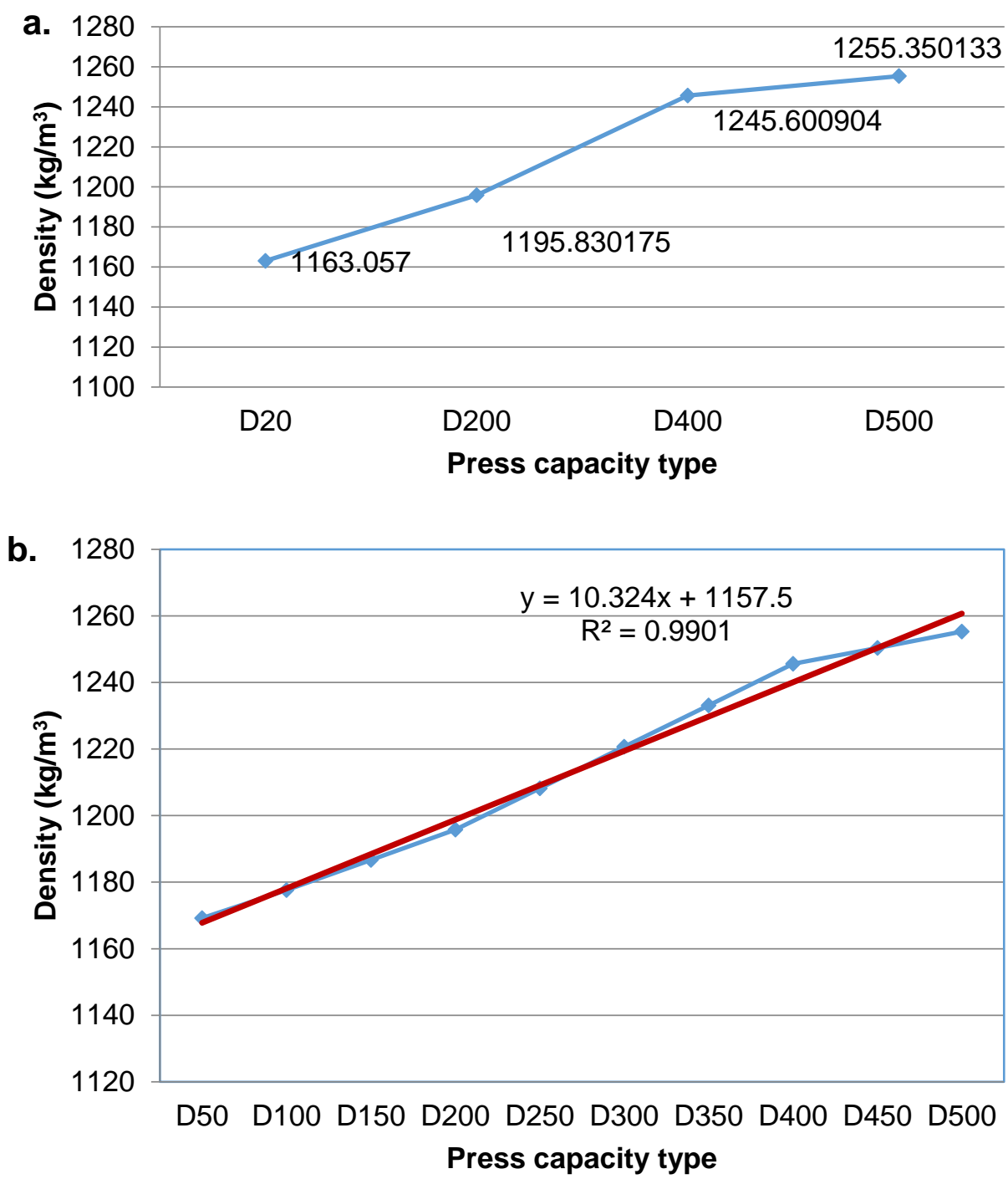

Fig. 6. Pellet density according to capacity (a) and density modeling according to capacity (b)

\section{The Caloric Properties of the Pellets}

The calorific value of the pellets had an average value of $20.0 \mathrm{MJ} \cdot \mathrm{kg}^{-1}$ for the high calorific value and $19.8 \mathrm{MJ} \cdot \mathrm{kg}^{-1}$ for the low calorific value. Increased moisture content of the pellets negatively influences the calorific power, and very high values of over $90 \%$ led to very low values, close to zero. These values are comparable to that of fire wood (Laohalidanond et al. 2017) and other materials (Tumuluru et al. 2011).

The caloric density determined by Eq.4 had an average value of $19,750 \mathrm{MJ} \cdot \mathrm{m}^{-3}$. This value corresponds to previously reported wood values. The caloric density obtained during the experiments express the bagging capacity of the pellets needed for production a small value greatly increases the volume of the bag or decreases the mass of the bag. This is an important aspect for production, which has to adapt easily when switching from one type of waste to another. 


\section{The Ash Content}

The ash content of the waste material from the corn cobs was on average $2.35 \%$, which is within the Austrian norm ÖNORM M7135 (2000), which provides a value below $6 \%$. Also, this value of ash content is below other waste of agriculture, such as straws or wood bark (Radulescu et al. 2018). The content of black ash (important in the combustion process, because no soot and smoke is produced above this value) was on average $24.8 \%$ (Fig. 7).
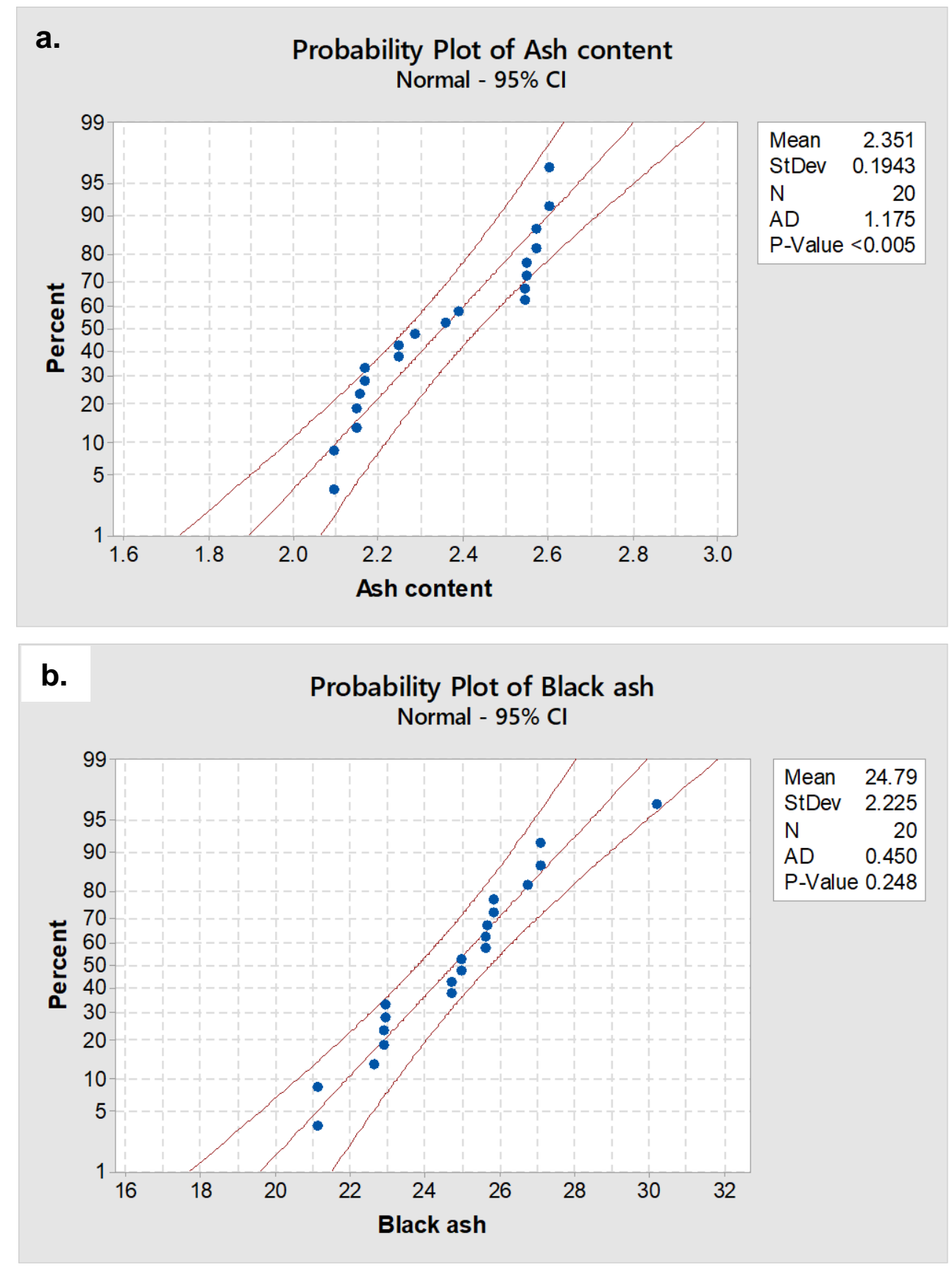

Fig. 7. Probably plot for black (a) and calcined ash content (b) 


\section{CONCLUSIONS}

1. A greater capacity in the pelletizing presses led to pellets with higher density, obtaining an increase of $92 \mathrm{~kg} \cdot \mathrm{m}^{-3}$.

2. Small particles with an average size of $1.7 \mathrm{~mm}$ obtained by shredding raw material of corn cobs are appropriate for pellet technology.

3. The ash content of $2.3 \%$ was good, lower than the value of the straw and wood bark but higher than beech fire wood.

4. By exceeding the minimal limits of European Norms all data confirmed that all data from the paper confirmed that corn cobs waste can be used in combustion as ecological pellets when press machine with flat die are used.

\section{REFERENCES CITED}

ASTM D3865-12 (2000)."Standard test method for gross calorific value of coal and coke," ASTM International, West Conshohocken, USA.

ASTM D-1102 (1984)."Standard test method for ash in wood," ASTM International, West Conshohocken, USA.

Biagini, E., Barontini, F., and Tognotti, L. (2014)."Gasification of agricultural residues in a demonstrative plant: Corn cobs," Bioresource Technol. 173, 110-116. DOI: 10.1016/j.biortech.2014.09.086

Biswas, B., Pandey, N., Bisht, Y., Singh, R., Kumar, J., and Bhaskar, T.(2017)."Pyrolysis of agricultural biomass residues: Comparative study of corn cob, wheat straw, rice straw and rice husk," Bioresource Technol. 237, 57-63. DOI: 10.1016/j.biortech.2017.02.046

ISO 1928 (2009)."Solid mineral fuels. Determining the gross calorific power by calorimeter bomb and calculus of net calorific power," International Organization for Standardization, Geneva, Switzerland.

Da Silva, J.C., de Oliveira, R.C., da Silva Neto, A., Pimentel, V.C., and dos Santos, A.A. (2015)."Extraction, addition and characterization of hemicelluloses from corn cobs to development of paper properties," Procedia Materials Science 8, 793-801.DOI: 10.1016/j.mspro.2015.04.137

DIN 51900-1(2000)."Determining the gross calorific value of solid and liquid fuels using the bomb calorimeter, and calculation of net calorific value - Part 1. General information," German Institute for Standardization, Berlin, Germany.

Ditzel, F., Prestes, E., Carvalho, B., Demiate, I., and Pinheiro, L. (2017)."Nanocrystalline cellulose extracted from pine wood and corncob,"Carbohyd.Polym.157, 1577-

1585.DOI: 10.1016/j.carbpol.2016.11.036

Djatkov, D., Martinov, M., and Kaltschmitt, M. (2018). "Influencing parameters on mechanical-physical properties of pellet fuel made from corn harvest residues," Biomass Bioenerg.119, 418-428.DOI: 10.1016/j.biombioe.2018.10.009

Du, C., Wu, J., Ma, D., Liu, Y., Qiu, P., Qiu, R., Liao,S., and Gao, D. (2015)."Gasification of corn cob using non-thermal arc plasma," Int. J. Hydrogen Energ.40(37), 12634-12649.DOI: 10.1016/j.ijhydene.2015.07.111

El-Sayed, S.A., and Khairy, M. (2017)." Preparation and characterization of fuel pellets 
from corn cob and wheat dust with binder," Iranica Journal of Energy and Environment 8(1),71-87. DOI:10.5829/idosi.ijee.2017.08.01.13

EN 14774-1 (2009)."Solid biofuels - Determination of moisture content - Oven dry method - Part 1: Total moisture," European Committee for Standardization, Brussels.

EN 14774-3 (2009)."Solid biofuels - Determination of moisture content - Oven dry method - Part 3: Moisture in general analysis sample," European Committee for Standardization, Brussels.

EN 15103 (2009)."Solid biofuels - Determination of bulk density," European Committee for Standardization, Brussels.

EN 15149-1 (2010)."Solid biofuels - Determination of particle size distribution - Part 1: Oscillating screen method using sieve apertures of $1 \mathrm{~mm}$ and above," European Committee for Standardization, Brussels.

EN 14775 (2010)."Determination of ash content," European Committee for Standardization, Brussels.

EN 14918 (2010)."Method for determination of calorific value," European Committee for Standardization, Brussels.

EN 15150 (2012)."Determination of particle density," European Committee for Standardization, Brussels.

Faustino, J., Pereira, L., Soares, S., Cruz, D., Paiva, A., Varum, H., Ferreira, J., and Pinto, J.(2012)."Impact sound insulation technique using corn cob particleboard,"Constr. Build. Mater.37, 153-159.DOI: 10.1016/j.conbuildmat.2012.07.064

Kaliyan, N., and Morey, R.V. (2010)."Densification characteristics of corn cobs," Fuel Process. Technol. 91(5), 559-565.DOI: 10.1016/j.fuproc.2010.01.001

Kundu, P., Kumar, S., Ahluwalia, V., Kansal, S., and Eleimalei, S. (2018)."Extraction of arabinoxylan from corn cob through modified alkaline method to improve xylooligosaccharides synthesis," Bioresource Technology Reports 3, 51-58. DOI: 10.1016/j.biteb.2018.01.007

Laohalidanond, K., Kongkaew, N., and Kerdsuwan, S. (2017)."Gasification behavior study of torrefied empty corn cobs," Energy Procedia138, 175-180.DOI: 10.1016/j.egypro.2017.10.146

Lao,F.,and Giusti, M. (2018). "Extraction of purple corn (Zea mays L.) cob pigments and phenolic compounds using food-friendly solvents," J. Cereal Sci. 80, 87-93. DOI: 10.1016/j.jcs.2018.01.001

Miranda, M. T., Sepúlveda, F. J., Arranz, J. I., Montero, I., and Rojas, C.V. (2018)."Analysis of pelletizing from corn cob waste," J. Environ. Manage.228, 303311.DOI: 10.1016/j.jenvman.2018.08.105

Mohlala, L., Bodunrin, M., Awosusi, A., Daramola, M., Cele, N., and Olubambi, P.(2016)."Beneficiation of corncob and sugarcane bagasse for energy generation and materials development in Nigeria and South Africa: A short overview," Alex. Eng. J. 55, 3025-3036.DOI: 10.1016/j.aej.2016.05.014

Njeumen Nkayem, D. E., Mbey, J. A., Kenne Diffo, B. B., and Njopwouo, D. (2016). "Preliminary study on the use of corn cob as pore forming agent in lightweight clay bricks: Physical and mechanical features," J. Build. Eng.5, 254-259.DOI: 10.1016/j.jobe.2016.01.006

Onsree, T., Tippayawong, N., Williams, T., McCullough, K., Barrow, E., Pogaku, R., and Lauterbach, J. (2019). "Torrefaction of pelletized corn residues with wet flue gas," Bioresource Technol.285,121330, DOI: 10.1016/j.biortech.2019.121330

ÖNORM M7135 (2000)."Pellets and briquettes -Requirements and test conditions," 
Austria Standards Institute, Austria Standards Institute, Vienna, Austria.

Paiva, A., Pereira, S., So, A., Cruz, D., Varum, H., and Pinto, J. (2012)."A contribution to the thermal insulation performance characterization of corn cob particleboards,"Energ. Buildings 45, 274-279.DOI: 10.1016/j.enbuild.2011.11.019

Pinto, J., Cruz, D., Paiva, A., Pereira, S., Tavares, P., Fernandes, L., and Varum, H. (2012)."Characterization of corn cob as a possible raw building material," Const. Build. Mater. 34, 28-33. DOI: 10.1016/j.conbuildmat.2012.02.014

Pinto, J., Paiva, A., Varum, H., Costa, A., Cruz, D., Pereira, S., Fernandes, L., Tavares, P., and Agarwal, J. (2011)."Corn's cob as a potential ecological thermal insulation material,"Energ.Buildings43(8), 1985-1990.DOI: 10.1016/j.enbuild.2011.04.004

Rădulescu, S., Lunguleasa, A., Pătrunjel, C., and Spirchez, C. (2018)."Pelletizing lignocelluloses biomass," ProLigno 14(2), 45-52.

Ragland, K.W., Aerts, D.J., and Baker, A. J. (1991)."Properties of wood for combustion analysis," Bioresour. Technol.37(2), 161-168. DOI: 10.1016/0960-8524(91)90205-X

Takada, M., Niu, R., Minami, E., and Saka, S. (2018)."Characterization of three tissue fractions in corn (Zea mays) cob," Biomass Bioenerg. 115,130-135. DOI: 10.1016/j.biombioe.2018.04.023

Tang, X., Ren, N., and Xu, J. (2013)." Evaluation of hydrogen production from corn cob with the mesophilic bacterium Clostridium hydrogen producers HR," Int. J. Hydrogen Energ.38, 9104-9110.DOI: 10.1016/j.ijhydene.2013.05.066

Tumuluru, J. S., Wright, C. T., Hess, J. R., and Kenney, K. L. (2011)."A review of biomass densification systems to develop uniform feedstock commodities for bioenergy application," Biofuels Bioprod.Bior.5(6), 683-707.DOI: 10.1002/bbb.324

Wang, F., Dang, Y., Tian, X., Harrington, S., and Ma, Y.Q. (2018)."Fabrication of magnetic activated carbons from corn cobs using the pickle liquor from the surface treatment of iron and steel," New Carbon Mater.33(4), 303-309.DOI: 10.1016/S18725805(18)60340-3

Wongsiriamnuay, T., and Tippayawong, N. (2015). "Effect of densification parameters on the properties of maize residue pellets," Biosyst. Eng. 139, 111-120. DOI: 10.1016/j.biosystemseng.2015.08.009

Yu, J., Zhao, Y., and Li, Y. (2014). "Utilization of corn cob biochar in a direct carbon fuel cell," J. Power Sources 270, 312-317. DOI: 10.1016/j.jpowsour.2014.07 .125

Zhang, L., Liu, S., Wang, B., Wang, Q., Yang, G., and Chen, J. (2015)." Effect of residence time on hydrothermal carbonization of corn cob residual," BioResources 10(3): 3979-3986. DOI: 10.15376/biores.10.3.3979-3986

Zhang, D., Wang, F., Zhang A., Yi, W., Li, Z., and Shen, X. (2019). "Effect of pretreatment on chemical characteristic and thermal degradation behavior of corn stalk digestate: Comparison of dry and wet torrefaction," Bioresource Technol.285: 239-246. DOI:10.1016/j.biortech.2018.12.044

Zhang, W., Zhang, X., Zhang, X., Yin, Z., Liu, Y., Fang, M., Wu, X., Min, X., and Huang, Z. (2019)."Lauric-stearic acid eutectic mixture/carbonized biomass waste corn cob composite phase change materials: Preparation and thermal characterization," Thermochim. Acta 674, 21-27. DOI: 10.1016/j.tca.2019.01.022

Article submitted: April 26, 2020; Peer review completed: June 4, 2020; Revised version received and accepted: June 18, 2020; Published: July 29, 2020.

DOI: 10.15376/biores.15.3.7058-7073 